\title{
TERRITÓRIOS DO INTERIOR, COESÃO TERRITORIAL E MODELOS DE GOVERNANÇA A PROPÓSITO DO PROGRAMA NACIONAL PARA A COESÃO TERRITORIAL
}

\author{
INLAND TERRITORIES, TERRITORIAL COHESION AND \\ GOVERNANCE MODELS \\ A REGARD TO THE NATIONAL PROGRAM FOR \\ TERRITORIAL COHESION
}

\begin{abstract}
Alcides A. Monteiro
Departamento de Sociologia, Faculdade de Ciências Sociais e Humanas, Universidade da Beira Interior (UBI) \& Centro de Investigação e Estudos de Sociologia (CIES-IUL). UBI, Estrada do Sineiro, 6200-209 Covilhã, Portugal. Email: alcidesmonteiro@ubi.pt
\end{abstract}

\begin{abstract}
Resumo: O presente artigo toma como ponto de partida o Programa Nacional para a Coesão Territorial, para debater a importância de modelos adequados de governança que apoiem a promoção do desenvolvimento e da coesão territoriais. Mais concretamente, advoga-se que os desafios da coesão territorial e a definição de um plano de desenvolvimento para o interior do país exigem, a par do quadro de medidas a implementar, a definição de um modelo de governança que seja alargada e confira o necessário protagonismo aos atores locais na busca de soluções para os desafios enfrentados.
\end{abstract}

Palavras-chave: território, governança, coesão territorial, desenvolvimento local.

\begin{abstract}
This article takes as its starting point the Programa Nacional para a Coesão Territorial [National Program for Territorial Cohesion], to discuss the importance of adequate governance models that support the promotion of territorial development and cohesion. More specifically, it is argued that the challenges of territorial cohesion and the definition of a development plan for the Portuguese inland territories require, along with the framework of measures to be implemented, the definition of a governance model that is broad and confers the necessary protagonism to the local actors in the search for solutions to the challenges faced.
\end{abstract}

Keywords: territory, governance, territorial cohesion, local development.

\section{Introdução ${ }^{1}$}

O texto que agora se apresenta toma como propósito analisar a importância da governança como prática fundamental no quadro da gestão de programas de desenvolvimento e de coesão territoriais. Tal reflexão é diretamente motivada pela divulgação, em finais de 2016, do Programa Nacional para a Coesão Territorial (ou PNCT), da responsabilidade da Unidade de Missão para a Valorização do Interior (UMVI).

Através do PNCT, o Governo de Portugal produziu um documento programático que tenta dar sentido à ideia de coesão territorial e a um plano concreto de 
desenvolvimento para o Interior do País. Na resolução do Conselho de Ministros $n^{\circ}$ 3/2016, de 14 de janeiro, que fixa a missão e o estatuto da UMVI, o Governo de Portugal assume

entre os seus objetivos prioritários a afirmação do 'interior' como um aspeto central do desenvolvimento económico e da coesão territorial, promovendo uma nova abordagem de aproveitamento e valorização dos recursos e das condições próprias do território e das regiões fronteiriças, enquanto fatores de desenvolvimento e competitividade.

E, na sequência, incumbiu a Unidade de Missão de criar, implementar e supervisionar um programa nacional para a coesão territorial, assim como de promover medidas de natureza interministerial tendentes ao "desenvolvimento do território do interior". O Plano inicial apresentava-se composto por três peças principais, a primeira das quais elenca mais de 160 medidas, maioritariamente de iniciativa governamental, a segunda define uma Agenda para o Interior e a terceira providencia uma leitura atualizada do "Interior em Números", ou seja, as bases para um diagnóstico sobre o país e a interioridade. Em julho de 2018 o Programa foi objeto de uma revisão, adicionando-se-lhe 63 medidas suplementares (UMVI, 2018).

Mas, ao mesmo tempo que produz um diagnóstico, estabelece uma agenda e define um vasto conjunto de medidas para a valorização do Interior, o documento em causa olvida, ou não inclui, outra peça essencial, aquela que diria respeito ao processo, ou "Método", que sustente estrategicamente a concretização da Agenda delineada. Mais concretamente, o documento produzido não fornece respostas claras para questões que reputamos de importantes: Como irá ser implementado o Programa nos diferentes territórios? Quais as formas de governação ou de governança a adotar? Qual o protagonismo das gentes que povoam estes territórios, e das organizações que as representam, na implementação de um programa que a elas se dirige e que ambiciona moldar o seu futuro? Em suma, o PNCT não evidencia devidamente a necessidade, cada vez mais amplamente reconhecida, de os territórios terem uma intervenção direta sobre o seu próprio destino. É a própria ex-coordenadora da UMVI quem o afirma, em artigo de opinião publicado no jornal O Público de 6 de novembro de 2017:

É urgente um programa integrado de apoio às aldeias e às suas comunidades, sustentado em novos modelos de governança, formal e informal, que aproximem a decisão do terreno, e que propiciem soluções articuladas e conformadas aos problemas específicos destes espaços territoriais.

É precisamente nesse sentido que este texto se orienta, o de sublinhar a importância da governança como um dos motores do desenvolvimento e da coesão territoriais 
(Torre, 2018) e como fundamento de uma abordagem que valorize o caráter endógeno e os protagonismos locais. Pelo que os seus objetivos passam por analisar o valor de uma perspetiva territorialista de desenvolvimento, indissociável de modelos de governança que sejam territorializados, colaborativos e amplamente participados. Para depois, através do exemplo concreto do PNCT, se concentrar sobre o modo como as políticas nacionais orientadas para a coesão territorial incorporam essa diretriz e, sobretudo, respondem aos desafios colocados em matéria de governança. $\mathrm{Na}$ parte final do artigo enfatizam-se algumas opções que, em nosso entender, devem influenciar os modelos de governança a desenhar: interpretar o território como um sistema dinâmico auto-organizado, operacionalizar sistemas que combinem verticalidade e horizontalidade nos processos de decisão e na execução concertada das medidas e, ainda, assumir a intervenção territorializada como um projeto de aprendizagem (a learning project).

Metodologicamente, seguiu-se um procedimento que começa pela análise de documentos oficiais, com particular ênfase sobre o PNCT, para, face às opções aí identificadas (ou à sua ausência) em matéria de políticas territorializadas e de modelos de governança a adotar, sustentar uma reflexão crítica sobre orientações estratégicas nestes domínios.

\section{Disparidades territoriais e promoção da coesão territorial}

Tanto no domínio do conhecimento como no campo da política concreta, a convivência com disparidades territoriais (por exemplo, dentro do espaço da União Europeia) e a perceção de que essas disparidades eram sinónimo de desigualdade, de fragilização e de depauperamento de alguns territórios face a outros, não constituíram só por si motivos evidentes para a eleição da coesão territorial como prioridade nas políticas de desenvolvimento. Principalmente, no que concerne a conceções e opções que favorecessem o "desenvolvimento territorial" de espaços não-urbanos e de baixa densidade populacional.

A história da incorporação deste princípio nas políticas europeias é conhecida e já foi sendo amplamente sistematizada em vários textos e documentos (Eurostat, 2016; Ferreira e Seixas, 2017; Santinha, 2014; Santinha e Marques, 2012; Medeiros, 2016; Veiga, 2002). Por outro lado, e ao assumir-se que a política também seja influenciada pelo conhecimento científico, pode-se pensar que o atraso e as indefinições na adoção do mencionado princípio também tenham a ver com a resistência de algumas teorias ao reconhecimento quanto à importância da variável "território" nas lógicas de desenvolvimento, isto é, à territorialização das políticas de desenvolvimento. 


\section{Orientações teóricas sobre desenvolvimento territorial}

Partilhamos a ideia de que o desenvolvimento é, por definição, um conceito endógeno, faz-se de dentro para fora. Por ocasião da crise grega que em 2010, tal como em Portugal, colocou o país na dependência de um programa de recuperação financeira conduzido pela Troika (Fundo Monetário Internacional, Banco Central Europeu e Comissão Europeia), uma canção local continha nas suas estrofes a seguinte mensagem: "tenho medo dos que decidem por mim, sem mim". Tal expressão é bem denotativa dos traumas gerados por modelos de desenvolvimento (ou "programas de ajustamento") exclusivamente exógenos, que se impõem à vontade interna e a subjugam. Assim como se têm revelado amiúde contraproducentes e de resultados duvidosos, particularmente no que concerne à ultrapassagem de "ciclos viciosos" de persistente ineficiência, desigualdade e dependência.

Esta abordagem endógena, territorialista ou place-based, ao conceito de desenvolvimento não é, ainda assim, pacificamente aceite e mobilizadora de consensos.

Num artigo de opinião publicado no portal VoxEU.org, de título "Regional Development Policies: Placed-Based or People-Centred?" , Indemet Gill (2010), então economista-chefe do Banco Mundial para a Europa e Região da Ásia Central, posiciona-se fortemente em favor de uma abordagem "espacialmente cega" ao desenvolvimento regional, argumentando que a política de base territorial poderia ser "bondosa e bem-intencionada", mas contraproducente. Na sua perspetiva "...o crescimento económico [entre regiões] será desequilibrado, e tentar espalhar a atividade económica - demais, muito longe ou muito cedo - é desencorajá-la.". O que não o impede de crer que o desenvolvimento possa ser inclusivo, a partir do momento em que os decisores políticos apostem em políticas de integração económica, ou seja, possibilitem que as pessoas residentes em zonas menos dinâmicas possam beneficiar da crescente concentração da atividade económica em alguns lugares. A alternativa proposta pelo economista-chefe do Banco Mundial é a de que os governos dos países apostem em três instrumentos de integração: a melhoria das instituições "espacialmente cegas", como sejam a educação, a saúde ou a segurança; o investimento em infraestruturas que facilitem a conexão espacial (transportes inter-regionais e serviços de informação e de comunicação); e incentivos a determinados "alvos" espacialmente identificados, que podem ser a agricultura, a agroindústria, os sistemas de irrigação ou a formação profissional.

Em resposta ao mencionado artigo de opinião, outros três economistas, Garcilazo, Oliveira Martins e Thompson (2010), advogam em contrapartida que a maximização do crescimento e do bem-estar obriga a que "em certas circunstâncias" as políticas económicas tenham em consideração as dimensões espacial ou 
territorial. A valorização das políticas territorializadas não é, na sua perspetiva, sinónimo de subestimação dos potenciais benefícios da aglomeração ou de negligência quanto ao aperfeiçoamento das instituições espacialmente cegas. Se as políticas regionais devem preocupar-se com as infraestruturas e o investimento público, não poderão todavia descurar os fatores endógenos, onde se incluem o nível e qualidade do capital humano, a inovação, a competição, a regulação dos mercados de trabalho e de produtos, o estímulo ao empreendedorismo. E sublinham, nessa matéria, a importância do contributo das políticas de desenvolvimento regional para a criação do capital humano e social, necessários à implementação de uma "abordagem de base territorial".

A dicotomia de posições que estes dois artigos ilustram não é recente. Pelo contrário, ela prolonga o debate despoletado pela crise financeira dos anos 70 do século XX. Em traços gerais, perante o desafio da espacialização do desenvolvimento, o confronto opera-se entre uma visão "funcionalista", em que dominam os conceitos de crescimento polarizado e os modelos tipo "centro-periferia", e um paradigma "territorialista", ou de desenvolvimento territorial, que aponta para a mobilização do "potencial endógeno" das regiões (Braga, 1993; Friedmann e Weaver, 1979).

A visão do território como um espaço plano, própria do paradigma funcionalista, é bem ilustrada no texto de Gill (2010) acima citado. Ou seja, remete para a integração funcional das regiões, para a redistribuição espacial dos impulsos de desenvolvimento a partir do centro para as periferias e por iniciativa das administrações centrais e, ainda, pela secundarização do fator humano face à valorização do fator capital. Como limites a esta estratégia serão apontáveis, entre outros, a redução dos territórios à condição passiva de recetáculo e a acentuação das disparidades territoriais por via de impulsos de desenvolvimento que não são disseminados de forma harmoniosa por todo o espaço e penalizam as "periferias" mais distantes. Do mesmo modo que se regista a prevalência de um "eugenismo territorial", que decorre da competição inter-territorial pela captação de investimentos públicos e privados a par da segregação institucional. A sobrevivência dos territórios mais fortes representa novos desequilíbrios e o agravamento do fosso entre regiões. A título de exemplo, podem mencionar-se as sistemáticas deslocalizações dos serviços públicos para os territórios com mais poder de lobby e mais bem defendidos do ponto de vista político. Como também a redução das redes públicas de ensino e de administração da justiça (fechamento de escolas e de tribunais) em nome da sua racionalização, penalizando territórios já de si desfavorecidos.

A inversão do sentido do desenvolvimento, agora interpretado como dinamizável a partir da base, não exclui a valorização das políticas nacionais e europeias de 
impulso a esse mesmo desenvolvimento. Do mesmo modo que não pode desvalorizar o necessário investimento em infraestruturas e serviços públicos de referência, na sua qualidade de elementos harmonizadores da qualidade de vida e das oportunidades em todo o espaço nacional. A abordagem territorialista distingue-se da anterior pela importância que confere à identidade e às dinâmicas de cada território na promoção do seu próprio desenvolvimento. Não se trata apenas de compreender, ou concretizar, o "onde", mas também o "como" e "com quem": "O desenvolvimento territorial designa um desenvolvimento endógeno e espacialmente integrado, alavanca o contributo dos atores que operam em múltiplas escalas e traz valor incremental aos esforços nacionais de desenvolvimento." (Romeo, 2015, p. 17).

Sob um mesmo quadro de referência comum, aquele que confere valor à endogeneidade e ao poder dos territórios, julgamos importante acentuar o modo como se têm vindo a produzir diferentes entendimentos, ou ângulos de abordagem, acerca da desejável territorialização do desenvolvimento: uma perspetiva que valoriza a identificação das vantagens competitivas e das "amenidades" enquanto fatores distintivos que impulsionam o desenvolvimento das regiões; uma outra mais centrada sobre a análise da complexidade dos sistemas locais e da sua capacidade para empreenderem um projeto local de desenvolvimento; e finalmente, a visão do desenvolvimento territorial a partir da pequena/ pequeníssima escala, aquela que observa o protagonismo das comunidades locais, ao nível da aldeia ou da vila, na gestão do seu próprio presente e futuro.

A primeira das perspetivas exprime-se sob a forma de análise interpretativa de aglomerados espaciais mais dinâmicos que pode ser encontrada, por exemplo, nos estudos sobre os distritos industriais que tiveram o seu apogeu no início dos anos 90 . E, por essa via, procurar possíveis modelos para outras regiões. O processo de identificação dos fatores que permitiam a certas regiões vingarem em contextos à partida desfavoráveis conduziu a uma primeira constatação, a de que os exemplos de sucesso não nascem de modo fortuito nem apenas por iniciativa das autoridades locais, mas resultam, sim, de dinâmicas de natureza endógena e do tempo longo do desenvolvimento. Depois, que a fórmula desse sucesso combina tanto estímulos de natureza técnico-económica como socioculturais. Na vertente técnico-económica marcam presença características como a divisão do trabalho entre PME especializadas, um sistema de regulação que combina mercado e reciprocidade, a constituição de redes de produção e inovação, o investimento em políticas de I\&D de base regional ou o estímulo ao empreendedorismo local. Quanto aos estímulos de natureza sociocultural, eles resultam de um "capital social" forte, por sua vez gerador de uma atmosfera de confiança, de reciprocidade e de capacidade de trabalho em regime de cooperação. Por fim, algumas análises têm vindo a insistir 
sobre as vantagens competitivas extraídas a partir da exploração das denominadas "amenidades" decorrentes do património natural e cultural: parques naturais, trilhos de fronteira, tradições únicas, bacias hidrográficas, etc..

A segunda perspetiva que identificamos é aquela que aponta à compreensão dos territórios como sistemas complexos e aos aspetos dinâmicos e de inovação que lhe possibilitam (re)afirmar-se e reagir às perturbações, internas e externas, positivas e negativas. Tal perspetiva já era vislumbrável nos estudos sobre os meios inovadores (Maillat, 1998), quando os mesmos se focalizaram sobre os elementos dinâmicos de inovação territorial, e o uso dos recursos imateriais (redes, liderança, conhecimento, aprendizagem) em favor processos de criação tecnológica. Prolonga-se agora sobre as análises sistémicas e a concretização da noção de "território-sistema". De acordo com Fabienne Leloup (2010), todo o sistema vivo, onde se inclui o território, obedece a propriedades específicas, que se exprimem em termos de totalidade, interatividade, organização e abertura. O princípio da totalidade ou globalidade implica que o sistema, enquanto um todo, é diferente da soma das partes. O princípio da interatividade remete para a compreensão de um sistema não apenas no que concerne aos elementos que o compõem mas também às relações que os juntam. Essas relações exprimem laços de dependência, de influença e de transformação. O princípio da organização diz respeito ao agenciamento das variáveis e à emergência de uma estruturação inerente ao sistema. Todo o sistema se define por referência a um ambiente, ou seja, a outros sistemas e variáveis exteriores ao objeto de estudo, o quarto princípio. Traduzida para a aproximação aos "territórios-sistema", ou à ideia de território como sistema auto-organizado (Pecqueur e Peyrache-Gadeau, 2010), esta perspetiva encara o desenvolvimento territorial não apenas como o resultado da presença de componentes produtivas e cognitivas, mas " ... antes de tudo como uma coordenação de atores" (Leloup, 2010, p. 692). O que significa atribuir protagonismo à capacidade coletiva de aprender (learning regions), de erigir e empreender um projeto comumente delineado, e de estruturar um modelo de governança democrática que facilite a coordenação entre atores (indivíduos e organizações), para além dos outros requisitos exigíveis por uma dinâmica de desenvolvimento territorial. Mais do que as vantagens competitivas, o desenvolvimento territorial depende das dinâmicas e processos que levam um coletivo a organizar-se e a reinventar-se.

A ideia do desenvolvimento local emerge nos anos 70 do século XX como movimento de resistência ou de contestação aos modelos economicistas orientados para a globalização dos mercados e a livre concorrência. A oposição ao modelo capitalista fazia-se por aquilo que ele significava de produção de bens supérfluos, mas, ao mesmo tempo, de agravamento das desigualdades e das bolsas de pobreza, 
de criação de situações de "dependência" das economias mais frágeis face às economias mais ricas, ou de subordinação dos valores culturais e societais a determinantes económicos (Stöhr e Taylor, 1981). Em contrapartida, aquela que se afirma como uma "corrente territorialista alternativa" estrutura uma proposta de desenvolvimento que repousa em dois pressupostos principais:

a necessidade da inversão da direcção dos processos de desenvolvimento (agora vistos como devendo ser a ' partir de baixo') e a aceitação da existência de um 'interesse territorial' que reúne a população de um dado espaço por identificação e por contradição com os interesses de outros espaços. (Pedroso, 1998)

A lógica associada a esta perspetiva é a de que o desenvolvimento exige um centramento das entidades territoriais sobre si próprias e a concessão de protagonismo aos que "lá estão" na identificação das necessidades e nos processos de decisão. Ou seja, uma referência ao caráter endógeno do desenvolvimento, que deve ser integrado e exige a participação dos interessados, assegurando "...que os participantes tenham o máximo controlo possível durante a ação e eles mesmos devam adquirir uma capacidade duradora para atuar" (Almeida, 2009, p. 120).

É este o espírito presente no Projeto ASAS - Aldeias Sustentáveis e Ativas que, entre 2011 e 2013, centrou o seu olhar sobre as comunidades rurais isoladas que constituem parte fundamental da ocupação demográfica do Interior de Portugal, aquele ao qual se destina o PNCT. O contacto com os territórios/aldeias e sobretudo com quem vive o rural das mais diversas formas permitiu a recolha de contributos para a definição de propostas de linhas políticas de atuação que estimulem a promoção de aldeias sustentáveis. Mais concretamente, à elaboração de um Programa Mínimo de Revitalização de Aldeia (Animar / ADCM / ICE, 2013). O pressuposto básico desse Programa é o “... de que uma verdadeira requalificação das aldeias pressupõe que todas elas, ou pelo menos a sua maior parte, sejam tidas em conta" (Animar / ADCM / ICE, 2013, p. 20) e elege quatro recomendações: 1) o estímulo à iniciativa da sociedade civil, elemento vital da dinâmica destes territórios, que o Estado Central (ou desconcentrado) deve deixar de encarar como mediadora das suas políticas mas como sujeitos ativos de processos de transformação; 2) que os municípios se assumam não como autores mas fundamentalmente como recursos dos atores individuais e coletivos que promovem o desenvolvimento local;3) que a necessária recapitalização do mundo rural, face à sua sucessiva descapitalização, se faça não pela mera canalização de investimento mas pela revalorização do local, isto é, colocar a tónica no "valor"; 4) e que os financiamentos de apoio ao desenvolvimento local se dirijam à intervenção multissectorial, à combinação de ações materiais com outras 
dirigidas à animação de processos e à qualificação de pessoas e organizações, à inovação social, contemplem a existência de um plano de governança, considerem escalas territoriais de intervenção diferenciadas e viabilizem intervenções plurianuais sujeitas a avaliação periódica.

Todas as mencionadas perspetivas assumem o pendor territorialista do desenvolvimento, colocando a tónica no carácter endógeno e nos protagonismos locais como motores do desenvolvimento. Ainda assim, organizam e interpretam de modo distinto a equação desejável que possa conduzir à dinamização dos territórios. Na ausência de uma via única, que também não seria desejável, crescem em importância as decisões e prioridades políticas que irão transpor os entendimentos teóricos para o plano da sua efetiva concretização.

\section{A interpretação política: Coesão territorial e governança local}

A consciência de que o mosaico da então Comunidade Económica Europeia (CEE) era marcado por grandes disparidades e ritmos de desenvolvimento diferenciados entre os Estados-Membro e, no interior de cada um, por idêntica dissemelhança entre regiões, levou a que o compromisso de uma política comunitária de Coesão Económica e Social fosse inscrito no quadro da adoção do Ato Único Europeu, em 1986. O combate às disparidades regionais far-se-ia sobretudo tendo como base uma distribuição equitativa dos fundos regionais, dotando as regiões mais vulneráveis de recursos para enfrentarem a concretização do mercado interno e a consequente eliminação de fronteiras internas técnicas e físicas que se opunham à livre circulação dos cidadãos e das mercadorias.

Mas é em 1997, com o Tratado de Amesterdão, que a agenda política europeia passa a incorporar de forma explícita o paradigma da Coesão Territorial (CT). Nesse documento a menção ao termo "Coesão Territorial" (artigo 16 do Tratado) surge juntamente com a expressão da necessidade em se promover a necessária Coesão Económica e Social do seio do espaço comunitário. Ainda assim, ao abrigo de uma orientação que relevava o caráter complementar da primeira perante a prioridade conferida à segunda (Medeiros, 2012).

A partir desse momento, a consideração do território como variável inerente à racionalidade das políticas públicas europeias para o desenvolvimento passa a ser mais evidenciada nos documentos oficiais, entre os quais se destacam a Agenda Territorial da União Europeia (2007), o texto do Tratado de Lisboa (2007), o Livro Verde sobre a Coesão Territorial (2008) e o relatório independente redigido por Fabrizio Barca, de título An Agenda for a Reformed Cohesion Policy A place-based approach to meeting European Union challenges and expectations (2009). 
No quadro da adoção da Agenda Territorial (Leipzig, maio de 2007) e consequente definição de um Programa de Ação para a sua implementação (Açores, novembro de 2007), os países da UE comprometerem-se a harmonizar o crescimento económico sustentável, a criação de empregos e o progresso social e ecológico, com a garantia de melhores condições e qualidade de vida e uma maior igualdade de oportunidades, em qualquer ponto territorial da União. Para tal, o plano de ação organizava-se em torno de seis prioridades territoriais: reforçar o desenvolvimento policêntrico e a inovação mediante o estabelecimento de redes entre cidades-regiões e cidades; criar novas formas de parceria e governança territorial entre áreas rurais e urbanas; promover conglomerados regionais de concorrência e inovação; reforçar e alargar as redes transeuropeias; promover uma gestão de risco transeuropeia, incluindo os efeitos das alterações climáticas; reforçar as estruturas ecológicas e os recursos culturais, que contribuem com valor acrescentado para o desenvolvimento (Parlamento Europeu, 2007).

O compromisso de harmonização assumido na Agenda Territorial vai posteriormente ser transposto para a letra do Tratado de Lisboa, onde o princípio da Coesão Territorial surge como terceiro pilar de atuação da UE, a par dos pilares da Coesão Económica e da Coesão Social. Ao mesmo tempo que se procedia à elaboração do dito Tratado, a CE avançou em 2008 para a publicação do Livro Verde sobre a Coesão Territorial Europeia, com um compromisso desde logo assumido sob a forma de subtítulo do documento, o de "tirar partido da diversidade territorial":

Da tundra gelada do círculo polar Árctico à floresta tropical da Guiana, dos Alpes às ilhas gregas, das cosmopolitas Londres e Paris às pequenas cidades e vilas seculares, a UE abriga uma diversidade territorial extraordinariamente rica. A coesão territorial procura alcançar o desenvolvimento harmonioso de todos estes territórios e facultar aos seus habitantes a possibilidade de tirar o melhor partido das características de cada um deles. Nessa medida, a coesão territorial é um factor de conversão da diferença em vantagem, contribuindo, assim, para o desenvolvimento sustentável de toda a EU. (Comissão Europeia, 2008)

Deste modo, a interpretação da coesão territorial extravasa a tradicional abordagem da busca de convergência entre as várias regiões, incluindo as mais desfavorecidas, para enfatizar a importância de se tirar partido da diversidade e da identidade territoriais, a favor de dinâmicas de desenvolvimento que valorizem as especificidades de cada território (Santinha, 2014).

Por fim, ejá com o objetivo do pós-2013 no horizonte, a Fabrizio Barca é solicitada pela Comissária da Política Regional Danuta Hübner a elaboração de um relatório independente dirigido à avaliação da eficácia da política de coesão e portadora de 
propostas para a sua reforma (Barca, 2009). O essencial da proposta avançada no Relatório radica na defesa de uma política de base territorial, enquanto estratégia de longo prazo destinada a ultrapassar a persistente subutilização do potencial e a promover a redução da exclusão social persistente em locais específicos, através de intervenções externas e de uma governança multinível. Face a outras estratégias que não assumem explicitamente um foco territorial ou mesmo "o escondem atrás de um ecrã de auto-proclamada cegueira espacial" (Barca, 2009, p. vii), o seu autor advoga as vantagens de formas de provisão de bens e de serviços que sejam integradas e adaptadas aos contextos, de intervenções públicas baseadas no conhecimento local, verificáveis e submetidas a escrutínio, ao mesmo tempo que são valorizadas as ligações entre os lugares. Para tal, e segundo Barca (2009), exige-se uma reforma dos modelos de governança, baseada em dez "pilares", onde se destacam a valorização do princípio da subsidiariedade, a articulação entre vários níveis de decisão com maior protagonismo para os níveis locais, a promoção do experimentalismo e a mobilização dos atores locais, bem como a valorização de processos de aprendizagem alimentados por dinâmicas de avaliação prospetiva e de impactos.

Na sequência do relatório de Barca (2009), mas também das orientações políticas saídas do Tratado de Lisboa e da adoção do "Método Aberto de Coordenação" (Borrás e Jacobsson, 2004; Daly, 2007), as instâncias da União Europeia têm vindo nos últimos anos a reforçar a ideia da governança como requisito estratégico essencial à prossecução de uma "mudança de paradigma" em matéria de políticas europeias de coesão (Barca, 2009, p. 107). A ambição enunciada é a de que a adoção de práticas de "boa governança" ou de "governança multinível" signifique um esbatimento da centralidade do Estado na condução das decisões públicas, e deslocação desse poder em duas direções (Monteiro e Horta, 2018): ao nível vertical, tanto num sentido descendente, pela transferência de alguns poderes para instâncias supranacionais (Comissão Europeia e outras), como no sentido descendente, pela delegação de competências e responsabilidades do governo central para os governos sub-regionais; ao nível horizontal, pelo envolvimento de agentes externos (organizações da sociedade civil, movimentos sociais, etc.) no ciclo das políticas públicas, não só no que concerne à implementação de medidas e provisão de serviços públicos, mas igualmente na definição conjunta das agendas políticas.

Todavia, a fácil adesão a muitos dos princípios que tendem a estar-lhe associados bem como a sua promoção ativa sob a forma de termo-solução perante a crescente complexidade dos problemas sociais e a necessidade de encontrar novas respostas para velhos problemas (Jessop, 2007), não evitam que a ideia de "boa governança" continue a ser ambígua e a traduzir-se em fórmulas de gestão muito diversas. À semelhança do que sucede com a apropriação do conceito de "território" 
e as interpretações relativas à territorialização do desenvolvimento, a adoção da ideia de governança tem-se concretizado em distintos cenários, com consequências muito distintas no que concerne à formatação dos processos de implicação e de deliberação (Jessop, 2007; Vaillancourt, 2007).

Entre as modalidades de coordenação de interesses adotadas, conta-se a opção por um formato de governança pública, em que a implantação de serviços coletivos ou quasi-coletivos é organizada diretamente pelos poderes públicos ou delegada a atores privados no quadro de uma regulação tutelar e hierárquica. Relativamente às formas clássicas de governo, um tal modelo de gestão territorial distingue-se pelo descentramento dos poderes em favor da sua re-territorialização, pela retirada do monopólio da execução das políticas às entidades políticas eleitas e pela implicação crescente de atores locais nas dinâmicas de desenvolvimento. Em contrapartida, a circunstância da prossecução de políticas de desenvolvimento e de promoção da coesão territorial continua subordinada a uma hierarquia de comando imperativa e burocrática, com os centros de decisão a manterem-se no governo nacional e respetivas estruturas político-administrativas. Aos agentes locais caberá a gestão desconcentrada das medidas, dos recursos e dos serviços, adaptável às necessidades e condições concretas de um território mas sempre orientada para a concretização de prioridades coletivas determinadas a partir de cima.

Outra fórmula que tem sido ensaiada é a da governança quasi-mercantil, que coloca em concorrência os potenciais prestadores de serviços (organizações da sociedade civil e prestadores privados com fins lucrativos) no acesso às subvenções atribuídas pelos poderes públicos para a produção de serviços coletivos ou quasi-coletivos. Tal opção decorre essencialmente da busca por uma mais eficiente alocação dos recursos e serviços, na linha das ideias associadas à governança empresarial e à nova gestão pública (John, 2001; Kooiman, 2003). A contratualização e consequente externalização da provisão de serviços, em regime concorrencial e aberto à participação de organizações privadas e parapúblicas, significa igualmente o envolvimento de novos agentes na implementação de medidas concretas, bem como pode contribuir para o reforço do empreendedorismo local. Assim como concorre para a potencial mercantilização e privatização da prestação de serviços públicos. O que tem levado alguns autores a invocarem um nexo relacional entre o conceito de "boa governança" e a ideologia neoliberal: uma hostilidade geral à presença do Estado na regulação social e a sua substituição por mecanismos não estatais, nomeadamente o mercado; e a preferência pela regulação social nacional e internacional por via de mecanismos não coercitivos, voluntariamente assumidos (códigos de conduta, boas práticas, soft law) (Santos, 2016). O que Guy Peters (2003) designa como possibilidade de uma "governança sem governo". 
Às hesitações e indefinições que têm rodeado a implementação de modelos de governança não será seguramente estranho o facto ela interferir diretamente com lógicas de poder. Tal como referem Åström, Granberg e Khakee (2011) ao fazerem recurso da "metáfora da tarte de maçã", todas as partes poderão tender a concordar com a importância da implementação de mecanismos de governança, conquanto essa fórmula não inclua uma "dentada" na sua fatia, ou seja, uma redistribuição do poder. E, particularmente, enquanto tal não signifique a partilha de poder de deliberação com agentes exteriores ao arco do poder público, central e local. Antevê-se, assim, um longo caminho a percorrer no que concerne à estabilização de um "método" que estabeleça um nexo virtuoso entre práticas de governança e promoção da coesão social.

Transposto agora o debate para o espaço nacional, o que tem sido feito em Portugal no que concerne à tradução prática do conceito de governança? Como está a ser interpretado no contexto de políticas de coesão territorial? E, mais ainda, que avanços na inclusão de novos atores no ciclo de políticas públicas? É no sentido de procurar respostas para estas questões que julgamos ser pertinente analisar, ao nível nacional, como as políticas orientadas para o desenvolvimento e promoção da coesão territoriais incorporam essa diretriz e, sobretudo, respondem aos desafios colocados em matéria de governança. Para tal, iremos servir-nos do exemplo do PNCT, na qualidade de política explicitamente dirigida para os propósitos acima sublinhados.

\section{Portugal e a Agenda para a Coesão Territorial}

Se em matéria de políticas de coesão territorial os documentos da União Europeia traçam as grandes linhas orientadoras e designam as prioridades da intervenção, fica ainda por dar um grande passo, aquele que permitirá converter esse programa político em medidas concretas. É uma tarefa que compete a cada país assumir, inclusive porque é reconhecido que a Agenda Europa 2020 não terá sido especificamente orientada para estratégias de política regional e local (Eurostat, 2016). Em Portugal, a tarefa de concretização do princípio da coesão territorial foi sendo adiada e carece de alguns procedimentos importantes, a crer na investigação feita por alguns autores. A partir da análise dos principais instrumentos de orientação estratégica, onde se incluíam o Programa Nacional de Desenvolvimento Rural PENDR 2007-2013, os Planos Regionais de Ordenamento do Território (2007-2011), o Quadro de Referência Estratégico Nacional - Portugal 2007-2013 e a Estratégia Nacional de Desenvolvimento Sustentável - ENDS 2015, Santinha e Marques (2012) identificaram a existência de três dimensões analíticas comuns à 
generalidade dos documentos no que concerne à promoção do desenvolvimento territorial, a saber, a promoção de ligações em rede e organização policêntrica do território, a equidade no acesso a Serviços de Interesse Geral e a aposta na governança territorial, na ótica de articulação de atores e políticas. Mas, ao mesmo tempo, atestaram a inexistência de medidas políticas concretas, de intervenção, que permitam a operacionalização do princípio de Coesão Territorial. Por outro lado, Ferreira e Seixas (2017) constatam a predominância nos Programas Nacionais de uma linha de política cujos objetivos/fins são territoriais e centrados sobre as pessoas, mas os instrumentos e meios são concebidos como institucionais e geridos por peritos. Exemplificam essa tendência a partir da dominância de um glossário do desenvolvimento territorial que é estabelecido de cima para baixo e é apenas dominável por uma rede fechada de peritos e decisores políticos, pela orientação de fundos estruturais para entidades territoriais (NUTS III) que resultam de uma nomenclatura estatística mas não possuem identidade socio-territorial específica, ou ainda pela criação de entidades gestoras dos fundos, as comunidades intermunicipais, também elas carentes de uma clara identidade socio-territorial. Todos estes sintomas acarretam evidentes prejuízos para a necessária democratização dos mecanismos de decisão e o envolvimento de novos protagonistas, que não os "suspeitos do costume", na interpretação e operacionalização das medidas de política territorial.

Porque de idêntico teor, cabe ainda dar relevo à mensagem transmitida pela equipa de avaliação do Programa Nacional de Ordenamento do Território (PNPOT), liderada por Cristina Cavaco, que, no âmbito da avaliação do Programa de Ação 2007-2013, menciona:

O PNPOT teve o mérito de, pela primeira vez, envolver num esforço conjunto os diversos setores da administração responsáveis por políticas públicas com incidência territorial, com vista à sua tradução integrada numa política de desenvolvimento de base territorial. Todavia, os sete anos de vigência do PNPOT evidenciam o fosso cultural e de mentalidades que, no âmbito da governança territorial e da territorialização das políticas públicas setoriais, é ainda um fator limitador à utilidade deste instrumento. (DGT, 2014, p. 16)

Pelo que, no quadro de uma revisão do Programa de Ação, incluem nas suas recomendações a de "Investir numa estrutura de governança permanente que assegure a adequada cooperação institucional e mantenha a atualidade e o agenciamento vertical e horizontal das opções estratégicas de base territorial do PNPOT" (DGT, 2014, p. 25).

Em suma, não só o princípio da Coesão Territorial integra hoje a expressão política das prioridades nacionais no que concerne à promoção de um 
desenvolvimento harmonioso do espaço e de ultrapassagem das condições de sistemático desfavorecimento que alguns territórios ainda enfrentam, como gradualmente se foram reconhecendo os principais pilares da sua promoção: coesão económica e social, policentrismo, sustentabilidade ambiental e modelos adequados de cooperação/governança multiníveis (Medeiros, 2012). Mas o ciclo está longe de completo, na medida em que são simultaneamente reconhecidas lacunas e indefinições em matéria de medidas concretas. Nomeadamente, no que concerne à operacionalização do princípio da governança, como a seguir se verá pelo exemplo do PNCT.

\section{PNCT: O diagnóstico e a agenda para o interior}

“O território continental português apresenta importantes diferenças no que respeita aos níveis de desenvolvimento económico e social, diferenças essas que se traduzem, no caso de algumas regiões, em importantes défices no plano da coesão económica e social" (MEPAT, 1999, pp. V-74). Quase vinte anos passados sobre a afirmação feita no quadro da elaboração de um Plano Nacional de Desenvolvimento Económico e Social 2000-2006, o cenário exposto na parte do PNCT que corresponde ao Diagnóstico sobre o país e a interioridade aponta para um agravamento das condições de desfavorecimento enfrentadas por "cerca de $2 / 3$ do território nacional", acentuando-se o despovoamento, envelhecimento e empobrecimento dessas regiões, numa "trajetória insustentável" que urge ser contrariada. Na circunstância, o entendimento de "Interior" é o de um território que partilha uma característica demográfica comum, a da baixa densidade populacional. E que, associada a esta, revela outros aspetos que configuram um "ciclo vicioso": outros traços demográficos (forte emigração e envelhecimento), económicos (escassez e fraca diversidade de atividades económicas, elevada taxa de desemprego), urbanos (insuficiente dimensão da maioria dos seus centros urbanos), institucionais (reduzido leque de entidades com atribuições e competências de proximidade) e relacionais (fracas redes de parcerias e deficientes taxas de participação e envolvimento da população) (UMVI, 2016, Anexo, 5-6). A situação descrita corresponderá a 165 concelhos num total de 278 que compõem o território continental, identificados

Sobre possíveis estratégias (um Programa) que permitam inverter esta tendência, a posição assumida pela UMVI é a de que o investimento deve ser feito em direção ao reconhecimento das especificidades dos territórios do Interior, assim como através da busca e implementação de medidas de discriminação positivas capazes de produzir essa inversão: 


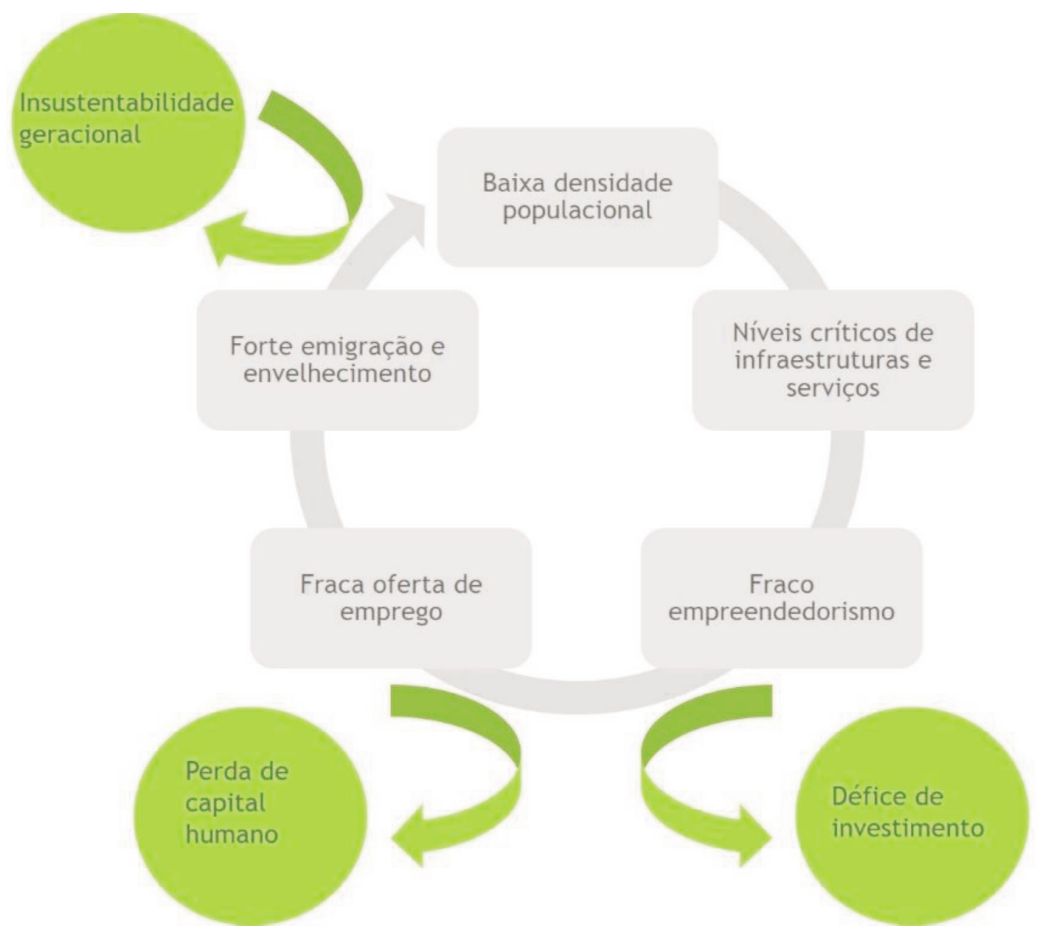

Figura 1 "Ciclo Vicioso" dos territórios de baixa densidade

Fonte: UMVI, 2016, Anexo, 6.

São várias as teorias de crescimento e desenvolvimento endógeno, e quase todas entendem o capital humano e a acumulação de conhecimento e de progresso tecnológico como alavancas. O quebrar do ciclo vicioso da baixa densidade passa, essencialmente, por dois mecanismos charneira: inversão das tendências demográficas e investimento. A fixação das populações, a formação do capital humano, a inovação e o desenvolvimento e as cidades funcionais são genericamente entendidas como a base para um crescimento e desenvolvimento territorial coesivo, inteligente, inclusivo e sustentável. (UMVI, 2016, Anexo, 8)

Destas opções programáticas decorre a eleição de um conjunto de mais de cento e sessenta Medidas concretas, que visam a operacionalização de cinco Eixos de Intervenção: Eixo 1. Um Território do Interior + Coeso, orientando a ação para promoção da inclusão social e a equidade entre territórios; Eixo 2. Um Território do Interior + Competitivo, que passa pela valorização dos recursos locais e incremento da atratividade; Eixo 3. Um Território do Interior + Sustentável, sobretudo através da valorização da diversidade geográfica e das amenidades 


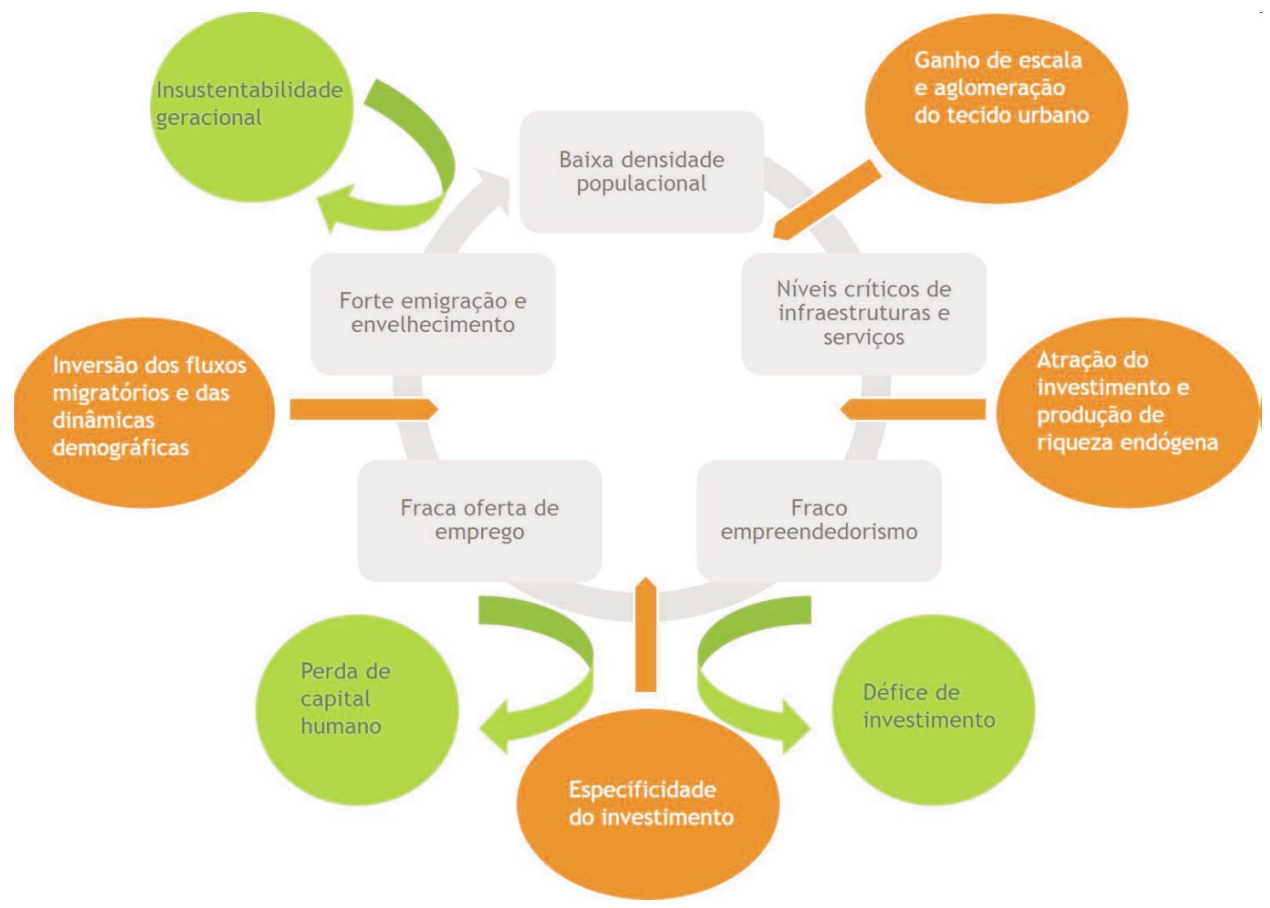

Figura 2 A quebra do "Ciclo vicioso"

Fonte: UMVI, 2016, Anexo, 8.

rurais; Eixo 4. Um Território do Interior + Conectado, nas dimensões litoral-interior, de fronteira e com a diáspora; e o Eixo 5. Um Território do Interior + Colaborativo, pela promoção da atuação interministerial, valorização das lideranças locais e capacitação institucional. O PNCT integra ainda uma "Agenda para o Interior", constituída por oito iniciativas direcionadas para questões e desafios que se colocam ao desenvolvimento dos territórios do Interior: Envelhecimento com Qualidade; Inovação da Base Económica; Capital Territorial; Cooperação Transfronteiriça; Relação Rural-Urbana; Acessibilidade Digital; Atratividade Territorial; Abordagens, Redes e Participação. Se no caso das Medidas a sua principal característica é a de serem precisas (fichas de caracterização), a sua operacionalização ser sobretudo atribuída à iniciativa governamental e já se apresentarem calendarizadas, já as Iniciativas da Agenda apelam à criação de oito grupos de trabalho, com participação alargada, que irão posteriormente proceder a um diagnóstico prospetivo da realidade e consequente proposta de um quadro de ação futura. 
O objetivo deste texto não é o discutir o PNCT na perspetiva das temáticas que elege para atuação prioritária (composição da Agenda para o Interior) e das medidas concretas selecionadas como potenciais promotoras do desenvolvimento. Deixamos essa tarefa para quem, entre economistas regionais, planeadores do território e outros investigadores, tem maior sensibilidade analítica sobre a matéria. Ainda assim, parece-nos importante sublinhar a similitude entre propostas distanciadas por quase 20 anos. Ou seja, entre o PNDES 2000-2006 e o PNCT mantêm-se constantes as intenções de privilegiar a formação do capital humano (emprego e qualificação dos recursos humanos), os ganhos de escala e o desenvolvimento integrado entre os centros urbanos e os meios rurais, o investimento na produtividade local assim como no correto aproveitamento dos recursos do território, o fomento da competitividade global, a aposta na criatividade e na inovação, ou a exploração das potencialidades transfronteiriças. O que nos deixa expectantes sobre quais as novas condições criadas, ou a criar, que permitam desta vez empreender a desejável inversão da tendência para a deterioração das condições de vida e das oportunidades no Interior do país.

\section{PNCT e modelo de governança: Da lacuna às possibilidades}

Da leitura do PNCT, ressalta a sua organização em direção a um conjunto de prioridades estratégicas e de medidas a operacionalizar no tempo estipulado e pelos promotores para tal designados. Mas, do mesmo modo que se focaliza sobre o desafio dos instrumentos e soluções a implementar, não concretiza de forma explícita o "Método" adequado a essa implementação. Ou seja, do sistema de governança que reporta à malha institucional sobre a qual pode repousar o restante do espírito reformista. Apenas num ponto breve, de três páginas, sobre "Implementação, acompanhamento e monitorização", é esclarecido que "A concretização das cento e cinquenta Medidas, dentro dos horizontes temporais fixados, está, sobretudo, dependente da atuação dos Ministérios que tutelam aquelas áreas de governação bem como dos principais promotores, em ambos os casos identificados na respetiva ficha." (UMVI, 2016, p. 145). Ao longo do restante documento constata-se a imputação da execução da maioria das medidas à iniciativa governamental, é feita menção à "desejada articulação com os agentes presentes no território" (UMVI, 2016, p. 6) ou à criação de grupos de trabalho para a operacionalização da Agenda para o Interior. A informação é muito escassa e revela uma lacuna importante em matéria de elucidação quanto ao modelo de governança que irá sustentar a implementação deste Programa nos territórios. 
Perante a ausência de um quadro estratégico explícito, julgamos legítimo pensar-se que a execução do PNCT irá ser concretizada seguindo a interpretação genérica dada pelo Estado português ao conceito de "governança multinível". Isto é, privilegiando a implementação de mecanismos de delegação de competências entre o governo central e as entidades (inter)municipais, segundo uma lógica que investe sobretudo no municipalismo e na verticalidade dos processos de decisão (Monteiro e Horta, 2018). Num país com uma forte tradição municipalista, o modelo de governança multinível português é apresentado como comportando três níveis (AD\&C, 2018, p. 138): o nível central é constituído pelo governo, os serviços da Administração Pública Central e as respetivas estruturas desconcentradas; o nível local é composto pelos municípios; o nível sub-regional é assegurado pelas entidades intermunicipais (duas áreas metropolitanas e 21 comunidades intermunicipais), que surgiram em 2013 para colmatar as limitações de escala enfrentadas pelos municípios considerados singularmente.

Partindo da iniciativa governamental, o PNCT volta a ser um exemplo de decisão centralizada. E de posterior delegação nas instâncias regionais e locais para a sua execução, com particular incidência nas autarquias (municípios e freguesias), associações de municípios, comunidades intermunicipais (CIM) e Comissões de Coordenação e Desenvolvimento Regional (CCDR). Ou seja, como nos fazem questão de lembrar projetos como o ASAS, a abordagem ao desenvolvimento e à coesão territoriais não contempla um conjunto de outros recursos/requisitos que potenciam uma maior capacidade de transformação. Entre eles, e sobretudo, a força propulsora da cooperação entre um amplo leque de atores locais, tanto ao nível da interpretação da realidade local nas suas especificidades - a "desocultação do oculto" (Animar/ADCM/ICE, 2013) - como de mobilização das sinergias em direção a projetos coletivos e da capacidade para aprender a empreender e a inovar. Um regime de cooperação que se torna tão mais profícuo quanto mais estabeleça uma forte conexão entre verticalidade e horizontalidade nos processos de decisão e na execução das soluções, envolvendo representantes da sociedade civil e dos setores produtivos e outras forças locais na totalidade dos momentos que compõem o ciclo de deliberação. E, simultaneamente, use o exercício concreto da política como via para o reforço de uma cultura de participação.

De acordo com a nossa interpretação necessidades (Monteiro, 2015; Monteiro e Ribeiro, 2008), a concretização de uma política de base territorial e de uma governança territorializada e participada implicam três opções fundamentais: como primeira, a de encarar o território não como espaço administrativo neutro, mas como um constructo e um sistema dotado de vitalidade e de interesses próprios; como segunda, a de entender a conceção (co-elaboração e co-construção) das políticas 
públicas como resultado da imbricação de diferentes níveis de poder, desde os infranacionais aos transnacionais; como terceira opção, a de assumir a intervenção territorializada como um projeto de aprendizagem, isto é, que se ultrapasse a frequente cativação do debate público por uma minoria de grupos de interesse bem organizados e a participação seja alargada a novos protagonistas (é participando que se aprende a participar), a par do exercício permanente da autoavaliação e revisão das práticas em função da aprendizagem adquirida.

Da interpretação do território como um sistema dinâmico auto-organizado, ou "território-sistema", já foi dado relevo num ponto anterior deste texto. Recorda-se que

neste contexto, os limites do território não são apenas definidos por referência a um perímetro político-administrativo (aspeto político) ou como um fragmento de um sistema produtivo nacional (aspeto económico), eles definem o lugar de intersecção de redes (físicas ou humanas, formais ou informais), de estratégias e de interdependências entre parceiros ligados entre si, o lugar de produção, de negociação, de partilha de um devir comum. (Leloup, Moyart e Pecqueur, 2005, p. 326)

Entre outras vantagens, esta abordagem potencia uma mais fácil identificação dos problemas comuns, o aproveitamento das sinergias próprias a sistemas já auto-organizados e a apropriação dos recursos não valorizados do território.

A implementação de um modelo de governança territorializado implica articulação entre fluxos horizontais e verticais de decisão, capazes de garantir um balanço de poder entre a democracia representativa e a democracia participativa. Ao Estado nacional continua a caber a função essencial de estabelecer prioridades para o país e garantir coerência entres os diversos domínios e instâncias de governo. Espera-se ainda dele que confira sentido e direção às decisões nacionais, refletindo a inserção do país em contextos globalizados, do mesmo modo que, numa postura flexível e dialogante, transmita orientações claras para os agentes locais e informe uma visão integrada sobre o futuro. Por sua vez, as decisões locais não podem ser reduzidas a atos de gestão, sem coerência nem consequências, mas também destituídas de recursos que possibilitem a sua concretização. Pelo contrário, a territorialização das políticas públicas só ocorrerá a partir do momento em que aos atores locais e outros relevantes (contemplando não só as autarquias e CIM, mas também representantes da sociedade civil em toda a sua amplitude), seja reconhecida a necessária autoridade para tomarem decisões. A instituição de um novo modelo de organização implica desde logo uma nova alocação de responsabilidades, tanto ao nível da co-elaboração das medidas de política como da co-construção de instrumentos de gestão e execução, naturalmente consonante com a natureza dos 
problemas enfrentados (Greffe, 2005). Concerne igualmente ao desenho institucional de instrumentos que possibilitem a atuação em parceria e em rede, não só ao nível da troca de informações como da articulação estratégica entre decisões. E remete ainda para a necessidade de instrumentos de coordenação de exercícios e dos recursos humanos, financeiros, legais e físicos.

Um dos maiores desafios dos modelos de governança em ensaio consiste na prossecução de formas alargadas de deliberação pública e de compromisso abrangente no quadro das dinâmicas de desenvolvimento. Contudo, a tendência sistémica registada é a de uma divisão clara e desproporcional entre um pequeno número de organizações, grupos ou cidadãos que se envolvem num grande número de dinâmicas de governança, e largos setores da sociedade escassamente implicados e marginalmente influenciadores das decisões finais. Alguns alegam que, focalizados na participação de um grupo restrito, se agilizam decisões, se consegue a participação dos mais capazes e se evitam processos longos e cansativos que dificilmente geram consensos. Contudo, também importa ponderar outros argumentos, como a perda de recursos potencialmente aportados por outros agentes, a fragilização das legitimidades ou a desresponsabilização das populações. Garantir o alargamento do campo de atores implicados implicará investir em contextos e processos (nomeadamente, metodologias) que favoreçam a participação mais alargada. Mas também garantir a existência de mais momentos em que essa participação se torna possível, na medida em que é participando que se aprende a participar. É preciso experimentar e aprender com essa experiência.

Ainda em favor de uma pedagogia da aprendizagem, importa investir em processos continuados de autoavaliação e de monitorização sobre a qualidade e eficácia dos mecanismos de governança implementados. A realidade das iniciativas e das experiências locais revela em muitos casos uma frágil atenção à eficácia e eficiência das políticas ensaiadas. A informalidade caracteriza muitos processos consultivos e de deliberação, não se isolam objetivos concretos a atingir em cada etapa, não se ensaiam novas metodologias participativas, carece-se do recurso mediadores qualificados que organizem e facilitem os processos. Como consequência, é frágil a capacidade para racionalmente analisar os resultados obtidos e operar em tempo útil as devidas correções, em favor da mobilização dos interesses territoriais.

\section{Conclusões}

A adoção de novas práticas de governança é atualmente reconhecida como uma das vias fundamentais à necessária renovação das políticas que promovam o desenvolvimento territorial. $\mathrm{O}$ denominador comum às várias interpretações, que 
não deixam depois de se traduzirem em diversas formas de proceder à sua implementação, é o de que a exploração do potencial transformador dos territórios implica a mobilização de novos intervenientes e recursos, uma parte significativa dos quais com origem local e experimentados na vivência direta dos problemas e necessidades em resolução.

OPNCT apresenta-se como uma iniciativa cujo foco é o de inverter o "ciclo vicioso" de exclusão, de imobilismo e de deterioração enfrentado pelo Interior do país, e promover um vasto leque de políticas públicas - medidas específicas e setoriais - que conduzam a "afirmar pela positiva" os territórios em causa. Territórios esses que correspondem a 165 municípios do espaço continental. No quadro do grande desafio imposto, que é estrutural e teima em agravar-se, não bastará seguramente a declaração de princípios e a renovação dos compromissos. Urge empreender ação concreta, tão concreta nas medidas a implementar quanto no "Método" a adotar para a sua concretização.

Da leitura dos documentos que expõem o Programa, divulgado em 2016 e objeto de uma pontual revisão em 2018 pela adição de novas medidas a executar, e onde se afirma o compromisso com "... uma nova abordagem de base local, mais colaborativa e mais próxima..." (UMVI, 2016, p. 4), constata-se que o mesmo carece de orientações quanto ao modelo de governança a implementar. O que nos faz depreender que, na ausência de um modelo dedicado, o Estado português irá prosseguir a abordagem da "governança multiníveis" como consonante com a centralização da capacidade de decisão no governo nacional, e posterior delegação de competências de execução e de provisão a entidades locais, privilegiadamente de natureza pública e intermunicipal. Isto é, ainda aquém de uma abordagem que, em favor da territorialização das políticas, da articulação entre fluxos horizontais e verticais de decisão, e do alargamento da participação a agentes exteriores ao arco do poder público, seja mais congruente com os princípios do desenvolvimento e da coesão territoriais.

Assim, sublinha-se a pertinência da governança territorializada e participada como modo de coordenação, por sua vez subordinada a três opções: encarar o território não como espaço administrativo neutro mas como um sistema dinâmico auto-organizado, operacionalizar sistemas que combinem verticalidade e horizontalidade nos processos de decisão e na execução concertada das medidas e, ainda, assumir a intervenção territorializada como um projeto de aprendizagem que contempla o alargamento da participação a novos atores portadores de renovados interesses e recursos. Em suma, um Programa que evidencie a importância de os territórios e as comunidades que os compõem terem uma palavra a dizer sobre o seu próprio destino, e tomarem-na. 


\section{Nota}

Por decisão pessoal, o autor do texto escreve segundo o novo acordo ortográfico.

\section{Referências}

AD\&C. (2018). Relatório do desenvolvimento \& coesão. Agência para o desenvolvimento e Coesão, I.P..

Almeida, A. F. (2009). Desarrollo comunitario y educación. Xàtiva: Dialogos-red.

Animar/ ADCM/ ICE (2013). ASAS - Programa Mínimo de Revitalização de Aldeia. Lisboa: Animar/ ADCM/ ICE.

Åström, J., Granberg, M., e Khakee, A. (2011). Apple pie-spinach metaphor: Shall e-democracy make participatory planning more wholesome?. Planning Practice $\mathcal{E}$ Research, 26(5), 571-586.

Barca, F. (2009). An agenda for a reformed cohesion policy: A place-based approach to meeting European Union challenges and expectations. Bruxelas: European Commission.

Borrás, S., e Jacobsson, K. (2004). The open method of co-ordination and new governance patterns in the EU. Journal of European Public Policy, 11(2), 185-208.

Braga, D. A. (1993). Entre o território e a função - Algumas notas sobre a problemática do desenvolvimento regional e local. A Rede para o Desenvolvimento local, 9/10, 11-15.

Comissão Europeia. (2008). Livro verde sobre a coesão territorial europeia - Tirar partido da diversidade territorial. Bruxelas: Comissão Europeia.

Daly, M. (2007). Whither EU social policy? An account and assessment of developments in the lisbon social inclusion process. Journal of Social Policy, 37(1), 1-19.

DGT. (2014). PNPOT - Avaliação do Programa de Ação 2007-2013. Lisboa: Direcção Geral do Território.

Eurostat. (2016). Eurostat regional yearbook 2016. Luxemburgo: Publications Office of the European Union.

Ferreira, F., e Seixas, P. C. (2017). Portugal 2020 and the new glossary of territorial development: Territorialization or neo-institutionalization?. Urbe. Revista Brasileira de Gestão Urbana, 9(3), 487-499.

Friedmann, J., e Weaver, C. (1979). Territory and function: The evolution of regional planning. Berkeley/ Los Angeles: University of California Press.

Garcilazo, J., Oliveira Martins, J., e Tompson, W. (2010). Why policies may need to be place-based in order to be people-centred. VoxEU.org - CEPR's policy portal. Disponível em http://voxeu.org/article/ why-policies-may-need-be-place-based-order-be-people-centred.

Gill, I. (2010). Regional development policies: Place-based or people-centred?. VoxEU.org CEPR's policy portal. Disponível em http://voxeu.org/article/ regional-development-policies-place-based-or-people-centredhttp:/voxeu.org/article/r egional-development-policies-place-based-or-people-centred. 
Greffe, X. (2005). The instruments of good governance. Em OECD (Ed.), Local governance and the drivers of growth (pp. 39-88). Paris: OECD.

Jessop, B. (2007). Promoting good governance, disguising governance failure: Reflections on policy paradigms and policy narratives in the field of governance. Zarz dzanie Publiczne, 2, 5-25.

John, P. (2001). Local governance in Western Europe. Londres: Sage.

Kooiman, J. (2003). Governing as governance. Londres: Sage.

Leloup, F. (2010). Le développement territorial et les systèmes complexes: Proposition d'un cadre analytique. Revue d'Économie Régionale E Urbaine, (4), 687-705.

Leloup, F., Moyart, L., e Pecqueur, B. (2005). La gouvernance territoriale comme nouveau mode de coordination territoriale?. Géographie, économie, société, 7(4), 321-332.

Maillat, D. (1998). Innovative milieux and new generations of regional policies. Entrepreneurship \& Regional Development, 10(1), 1-16.

Medeiros, E. (2012). Territorial cohesion: A conceptual analysis. Lisboa: CEG-IGOT, Universidade de Lisboa. Disponível em http://ww3.fl.ul.pt/pessoais/EduardoMedeiros/docs.

Medeiros, E. (2016). Is there a rise of the territorial dimension in the EU Cohesion Policy?. Finisterra, 51(103), 89-112.

MEPAT. (1999). Plano Nacional de Desenvolvimento Económico e Social 2000-2006. Lisboa.

Monteiro, A. A. (2015). Espinafres, tartes de maçã e governança local. Vez e Voz, (Edição Especial - março), 28-35.

Monteiro, A. A., e Ribeiro, F. B. (Orgs.) (2008). Redes sociais: Experiências, políticas e perspectivas. Ribeirão: Húmus.

Monteiro, S., e Horta, A. (2018). Governança multinível em Portugal: Fundamentos teórico-conceptuais (AD\&C Working Paper $n^{\circ} 3$ ). Lisboa: AD\&C.

Parlamento Europeu. (2007). Seguimento da Agenda Territorial e da Carta de Leipzig: Para um programa de acção europeu de desenvolvimento do espaço e coesão territorial - Nota ad-hoc. Bruxelas: Parlamento Europeu.

Pecqueur, B., e Peyrache-Gadeau, V. (2010). Fondements interdisciplinaires et systémiques de l'approche territoriale Introduction. Revue d'Économie régionale $\mathcal{E}$ urbaine, (4), 613-623.

Pedroso, P. (1998). Formação e desenvolvimento rural. Oeiras: Celta.

Peters, B. G. (2002), Governance: A garbage can perspective. Vienna: Institute for Advanced Studies.

Romeo, L. (2015). What is territorial development?. GREAT insights Magazine, 4(4).

Santinha, G. (2014). O princípio de coesão territorial enquanto novo paradigma de desenvolvimento na formulação de políticas públicas: (Re)Construindo ideias dominantes. EURE, 40(119), 75-97.

Santinha, G., e Marques, T. (2012). A integração do princípio de coesão territorial na agenda política: O caso português. Revista de Geografia e Ordenamento do Território, (2), 215-244. 
Santos, B. S. (2016, 10 de janeiro). Democratizar está muito para além do Estado e do sistema político. Público. Disponível em

https://www.publico.pt/2016/01/10/politica/noticia/democratizar-esta-muito-p ara-alem-do-estado-e-do-sistema-politico-1719575.

Stöhr, W. B., e Taylor, D. R. (1981). Development from above or below? The dialectics of regional planning in developing countries. Chichester: Wiley.

Torre, A. (2018). Les moteurs du développement territorial. Revue d'Économie Regionale $\mathcal{E}$ Urbaine, 4, 711-736.

UMVI. (2016). Programa Nacional para a Coesão Territorial. Lisboa: Governo de Portugal.

UMVI. (2018). Programa de Valorização do Interior. Revisão PNCT: Novas medidas. Lisboa: Governo de Portugal.

Vaillancourt, Y. (2007). Vers un État stratège partenaire de la société civile. Cahiers du Centre de recherché sur les innovations sociales. Cahiers du Centre de recherche sur les innovations sociales (CRISES), Collection Études théoriques, $\mathrm{n}^{\circ}$ ET0708.

Veiga, J. E. (2002). A face territorial do desenvolvimento. Interações, 3(5), 5-19.

Data de submissão: 31/08/2018 | Data de aceitação: 13/02/2019 